\title{
Transesterification of Palm Oil to Biodiesel and Optimization of Production Conditions i.e. Methanol, Sodium Hydroxide and Temperature
}

\author{
Shaila Siddiqua, Abdullah Al Mamun, Sheikh Md. Enayetul Babar \\ Biotechnology and Genetic Engineering Discipline, Khulna University, Khulna, Bangladesh
}

Email address:

siddiquashaila@gmail.com (S. Siddiqua), mamun.bge.ku@gmail.com (A. A. Mamun), babarku@yahoo.com (S. Md. E. Babar)

\section{Email address:}

Shaila Siddiqua, Abdullah Al Mamun, Sheikh Md. Enayetul Babar. Transesterification of Palm Oil to Biodiesel and Optimization of Production Conditions i.e. Methanol, Sodium Hydroxide and Temperature. Journal of Energy and Natural Resources.

Vol. 4, No. 3, 2015, pp. 45-51. doi: 10.11648/j.jenr.20150403.12

\begin{abstract}
Biodiesel is an alkyl ester of long chain fatty acids and considered as an alternative to lower the appalling consequence of fuel on the environment. It is produced by transesterification of a fat or oil with a short chain primary alcohol like methanol and alkali like sodium hydroxide $(\mathrm{NaOH})$. Palm oil (Elaeis guineensis) was used as source to produce biodiesel and Box Behnken experimental design was applied to see the effect of various process parameters, i.e. methanol quantity, alkali concentration and temperature for the optimization of calorific value of biodiesel. Response surface plots and contour plot were created in order to perceive the optimum condition. Though, all the three variables significantly affected the calorific value of the palm biodiesel, but it was found that methanol was more effective variable than alkali concentration and temperature. It was observed that $12.5 \mathrm{ml}$ methanol $/ 50 \mathrm{ml}$ oil and $0.4 \mathrm{gm} \mathrm{NaOH} / 50 \mathrm{ml}$ oil and $55^{\circ} \mathrm{C}$ temperature were optimum condition, where the calorific value of palm biodiesel is $9297.206 \mathrm{kcal} / \mathrm{kg}$.
\end{abstract}

Keywords: Biodiesel, Palm Oil, Transesterification, Calorific Value, Optimization

\section{Introduction}

It is anticipated that the primary energy in every form from gasoline and diesel to the non-commercial fuels like biomass consumption of the entire world in a year is almost equivalent to ten thousands million tons of oil [1]. An increase of energy consumption will rise to forty nine percent from year 2007 to 2035 is conjectured by analyzing total vend energy of the world [2]. By considering the possibility of reduction of the oil production globally and the continuous rise of energy requirement for every day, the search for alternative fuel is must to meet the energy demand. Hence, biodiesel as a source of energy could become the alternative fuel. When the fossil fuel is burned it releases carbon dioxide $\left(\mathrm{CO}_{2}\right)$ at an amount of near about twenty one billion in one year, in which merely half of the anticipated quantity of $\mathrm{CO}_{2}$ was captivated by means of natural process. Thus, every year an excess of 10.65 billion tons of $\mathrm{CO}_{2}$ added to the atmosphere [3]. Whereas, biodiesel burning emits less than eighty percent carbon dioxide and emissions of sulfur dioxide tends to zero [4].

An alternative type of petroleum diesel fuel is biodiesel, generally made from different vegetable oils, waste products, animal fat or recycled restaurant greases. Biodegradability and emission of minimal amount of air pollutants make it more environment friendly fuel than petroleum fuel. Basically, biodiesels are the long-chain alkyl esters derived from organic sources, resulted from the chemical reaction of lipids (e.g., vegetable oil, animal fat) and alcohol termed as transesterification process. The use of alcohol and base or acid catalyst is extensively used in chemical conversion process to generate methyl esters from the base oil. Glycerin is formed as a by-product of the transesterification process [5, 6]. It differs from the vegetable and waste oil which directly used in fuel engine requires conversion of the diesel engine, as it is made in proper diesel forms to utilize in the regular diesel engine, whether use it in its pure form or combination with petroleum diesel $[7,8]$.

The demand for the production of biodiesel is increasing throughout the world because of its high quality fuel properties that makes it easy to use in almost every type of diesel engine. Industrial scale manufacturing of palm 
biodiesel is the way to go as it will not only bridge the energy deficit in the near future, but also it will deal with the ever increasing outcry of environmental contamination. Fossil fuel acts in the opposite because it defiles the environment in a great extend [9].

Biodiesel production process optimization refers to identify the most favorable values of raw ingredients. For optimization of chemical method of palm biodiesel production Box-Behnken designs [10] were used. The BoxBehnken design, which is the response surface methods (RSM), is a very useful statistical tool to optimize multiple variables for predicting the best performing conditions by using a minimum number of experiments [11]. In this study, we extracted biodiesel from palm oil by chemical method [12] and applied Box-Behnken designs as statistical tool to optimize the values of pre-eminent element (methanol and sodium hydroxide concentration and temperature) of biodiesel production process.

\section{Materials and Methods}

\subsection{Materials}

The research work was carried out with palm oil collected from local market (Khulna, Bangladesh). Methanol and sodium hydroxide used in the transesterification reaction were supplied by Merck, Germany.

\subsection{Method of Biodiesel Production}

In transesterification reaction, three moles of methanol react with one mole of triglyceride. The reaction is slowed by mass transfer limitations since at the start of the reaction the methanol is only slightly soluble in the oil and later on, the glycerin is not soluble in the methyl esters. Since the catalyst tends to concentrate in the glycerin, it can become unavailable for the reaction without agitation. The procedure of making biodiesel follows several steps.

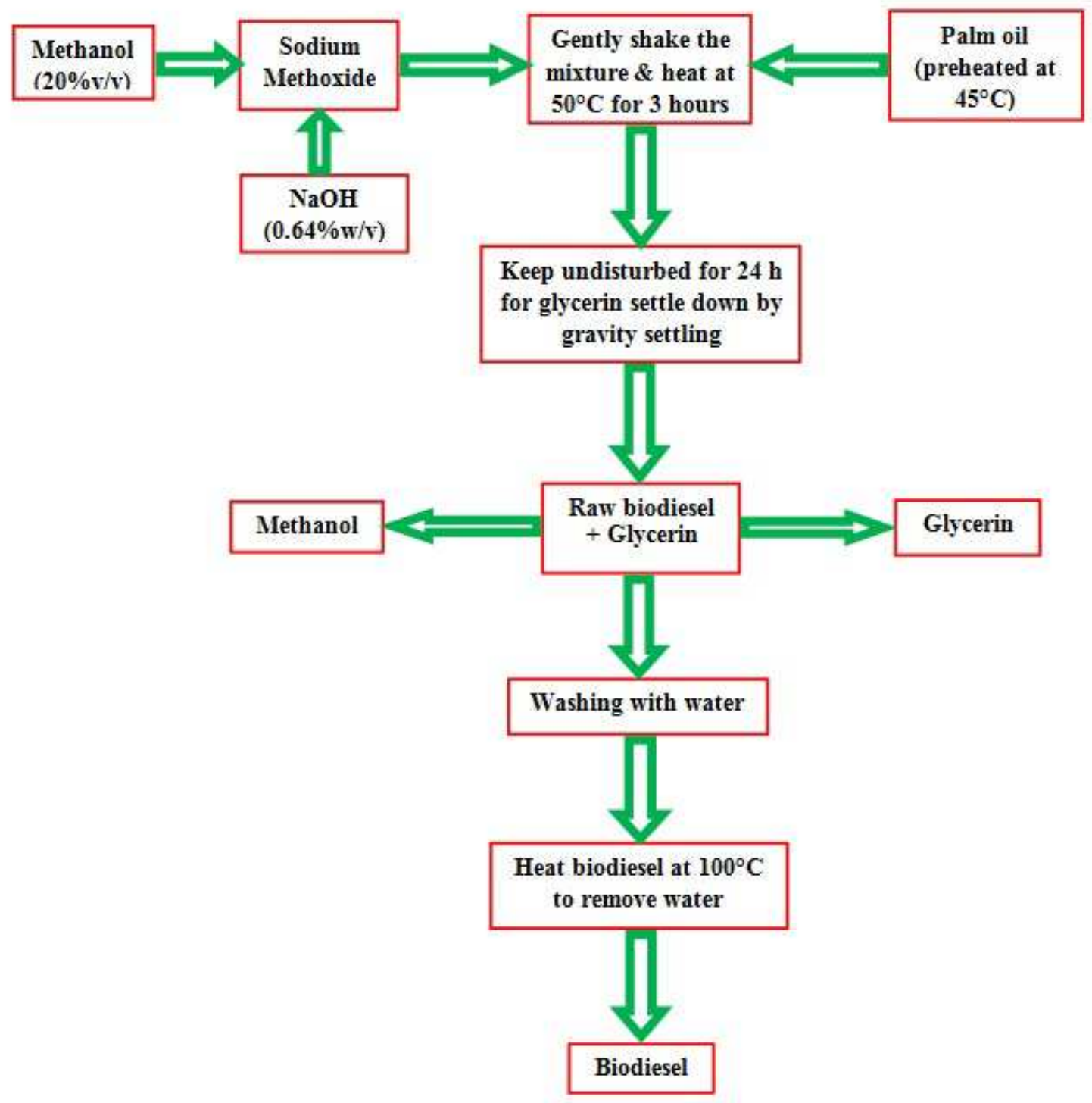

Figure 1. Flow diagram of biodiesel production from palm oil [12].

Mixing of alcohol and catalyst: The catalyst sodium hydroxide, at an amount of $0.8 \%$ of vegetable oil was 
dissolved in the methanol at an amount of $25 \%$ vegetable oil by hand shaking and whirling. The methanol and catalyst sodium hydroxide were mixed properly. Water must be avoided as a solvent in this stage.

Reaction: The alcohol catalyst mix was then poured into a conical flask and the oil was added. The palm oil was heated at $45^{\circ} \mathrm{C}$ temperature before mixing with alcoholcatalyst mixture. After adding oil the system keeps air tight to prevent the loss of alcohol. The reaction mix was kept just below the boiling point of the alcohol to speed up the reaction and the reaction took place. The reaction was held under constant temperature around $50-60^{\circ} \mathrm{C}$ on the water heater. Reaction time varies from 1 to 8 hours.
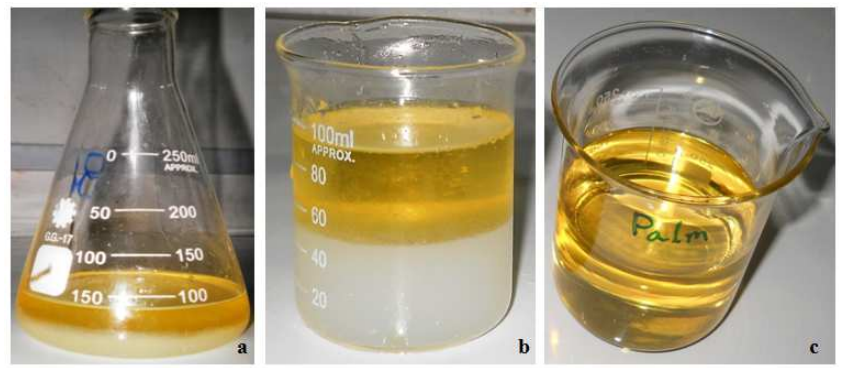

Figure 2. Different steps of biodiesel. (a) Raw biodiesel and glycerin, (b) washing of biodiesel, and (c) pure palm biodiesel.

Separation: Once the reaction was completed, two major products exist- biodiesel and glycerin. The glycerin which was much denser than the biodiesel, separated by gravity separation and the biodiesel was ready for further processing. The glycerin separation steps were usually accomplished by gravity settling or with a centrifuge.

Alcohol Removal: Remaining methanol (3\% to 6\%) in the biodiesel was removed by vaporization since methanol has a propensity to work as a co-solvent for soap present in the biodiesel.

Methyl Ester Wash: After the methanol had been removed, the biodiesel needs to be washed to remove residual free glycerin, methanol, soaps and catalyst. This

$$
Y=A_{0}+A_{1} X_{1}+A_{2} X_{2}+A_{3} X_{3}+A_{4} X_{1} X_{2}+A_{5} X_{1} X_{3}+A_{6} X_{2} X_{3}+A_{7} X_{1}^{2}+A_{8} X_{2}^{2}+A_{9} X_{3}^{2}
$$

Where $\mathrm{Y}$ is the response (calorific value); $\mathrm{X}_{1}$ methanol, $\mathrm{X}_{2} \mathrm{NaOH}$ concentration, $\mathrm{X}_{3}$ temperature; $\mathrm{A}_{0}$ the regression coefficient, $\mathrm{A}_{1}-\mathrm{A}_{3}$ are the linear coefficients, $\mathrm{A}_{4}-\mathrm{A}_{6}$ the cross product coefficients, and $\mathrm{A}_{7}-\mathrm{A}_{9}$ are the quadratic coefficients. The regression analysis, statistical significance and analysis of variance (ANOVA) were carried out using Microsoft Office Excel. Surface plots and contour plot were developed using the same software along with Sigma Plot software.

\section{Results and Discussion}

For the optimization of chemical parameters of biodiesel production process from palm oil we used the most efficient method found in our previous work [12]. The Box-Behnken design was employed as a statistical means to optimize this was done by liquid-liquid extraction by mixing water with the biodiesel and gently agitating and the soap was separated by gravity separation. The washing process was done 3-4 times until the wash water no longer picks up soap.

Methyl Ester Drying: Remaining water present in the washed biodiesel was removed by heating at $100^{\circ} \mathrm{C}$ for 10 minutes. Finally usable $100 \%$ pure biodiesel was extracted.

\subsection{Experimental Design}

The Box-Behnken design is a type of response surface methodology (RSM) used as the experimental design. It is an independent quadratic design. These designs are rotatable (or near rotatable) and require three levels of each factor. Three variables were methanol $\left(\mathrm{ml}, \mathrm{X}_{1}\right), \mathrm{NaOH}(\mathrm{gm}$, $\left.\mathrm{X}_{2}\right)$ and temperature $\left({ }^{\circ} \mathrm{C}, \mathrm{X}_{3}\right)$; three levels are $+1,0$ and -1 respectively. Table 1 represents three variables and their coded levels. The central values (zero level) chosen for experimental design were: methanol- $\mathrm{X}_{1}(12.5 \mathrm{ml}$ i.e. $0.25 \mathrm{ml}$ methanol $/ \mathrm{ml}$ oil $), \mathrm{NaOH}-\mathrm{X}_{2}(0.4 \mathrm{gm}$ i.e. $0.008 \mathrm{gmNaOH} / \mathrm{ml}$ oil) and temperature- $\mathrm{X}_{3}\left(55^{\circ} \mathrm{C}\right)$.

Table 1. Range of independent variables in the experimental design.

\begin{tabular}{llll}
\hline \multirow{2}{*}{ Variables } & \multicolumn{3}{l}{ Coded levels } \\
\cline { 2 - 4 } & $\mathbf{+ 1}$ & $\mathbf{0}$ & $\mathbf{- 1}$ \\
\hline Methanol $\left(\mathrm{ml}, \mathrm{X}_{1}\right)$ & 11 & 12.5 & 14 \\
$\mathrm{NaOH}\left(\mathrm{gm}, \mathrm{X}_{2}\right)$ & 0.3 & 0.4 & 0.5 \\
Temperature $\left({ }^{\circ} \mathrm{C}, \mathrm{X}_{3}\right)$ & 50 & 55 & 60 \\
\hline
\end{tabular}

Where each methanol and $\mathrm{NaOH}$ concentration is given for $50 \mathrm{ml}$ oil

Coefficients found from regression analysis were used in the second order polynomial equation to generate predicted value. Surface plots were produced using predicted value to find out the possible optimum condition.

The second order polynomial equation for three responses:

production process [13]

\subsection{Process Optimization by Box-Behnken Method}

In transesterification process methanol (alcohol) reacts with palm oil to form fatty acid alkyl esters (biodiesel) and glycerin. This reaction needs heat and sodium hydroxide as a strong base catalyst. Thus the important factors for the of palm oil (vegetable oil) are methanol, alkali $(\mathrm{NaOH})$ and temperature. Hence, these factors are considered as the independent variables and their effects on calorific value of biodiesel are studied using Box- Behnken design of Response surface methodology (RSM). production of alkaline catalyzed transesterification reaction 
Table 2. The Box-Behnken design matrixes employed for three independent variables (methanol, $\mathrm{NaOH}$ and temperature) with observed calorific values for palm biodiesel.

\begin{tabular}{lllll}
\hline $\begin{array}{l}\text { Run } \\
\text { No. }\end{array}$ & $\begin{array}{l}\text { Methanol } \\
\left(\mathbf{X}_{\mathbf{1}}\right)(\mathbf{m l})\end{array}$ & $\begin{array}{l}\mathbf{N a O H} \\
\left(\mathbf{X}_{\mathbf{2}}\right)(\mathbf{g m})\end{array}$ & $\begin{array}{l}\text { Temperature } \\
\left(\mathbf{X}_{\mathbf{3}}\right)\left({ }^{\circ} \mathbf{C}\right)\end{array}$ & $\begin{array}{l}\text { Calorific value } \\
(\mathbf{c})(\mathbf{k c a l} / \mathbf{k g})\end{array}$ \\
\hline 1 & 11 & 0.3 & 55 & 9120.511 \\
2 & 14 & 0.3 & 55 & 9136.32 \\
3 & 11 & 0.5 & 55 & 9131.531 \\
4 & 14 & 0.5 & 55 & 9145.291 \\
5 & 11 & 0.4 & 50 & 9156.396 \\
6 & 14 & 0.4 & 50 & 9123.81 \\
7 & 11 & 0.4 & 60 & 9124.825 \\
8 & 14 & 0.4 & 60 & 9166.736 \\
9 & 12.5 & 0.3 & 50 & 9168.34 \\
10 & 12.5 & 0.5 & 50 & 9202.726 \\
11 & 12.5 & 0.3 & 60 & 9245.954 \\
12 & 12.5 & 0.5 & 60 & 9240.515 \\
13 & 12.5 & 0.4 & 55 & 9297.221 \\
14 & 12.5 & 0.4 & 55 & 9297.199 \\
15 & 12.5 & 0.4 & 55 & 9297.21 \\
\hline
\end{tabular}

The results of Box-Behnken design experiments for studying the effects of three independent variables, viz., methanol, $\mathrm{NaOH}$ and temperature on calorific value are presented in Table 2. These values are used for analysis of regression where Microsoft office excel tool "data analysis" is used. 95\% confidence level is kept and the calculation of regression gives the coefficient values $\left(\mathrm{A}_{0}\right.$ to $\mathrm{A}_{9}$ of Equation1). For each response different set of these coefficients were obtained. At the condition of the central values (zero level) i.e. $12.5 \mathrm{ml}$ methanol, $0.4 \mathrm{gm} \mathrm{NaOH}$ and $55^{\circ} \mathrm{C}$ temperature the calorific value is $9297.221 \mathrm{kcal} / \mathrm{kg}$.

From regression analysis all nine coefficients are used in making the response equation. The second order polynomial equations for each response were found as follows:

$$
\begin{gathered}
Y(c)=-3031.33+1174.911 X_{1}+4893.243 X_{2}+141.3478 X_{3}-3.4155 X_{1} X_{2}+2.483217 X_{1} X_{3}-19.9124 X_{2} X_{3}- \\
52.2752 X_{1}^{2}-4617.75 X_{2}^{2}-1.46595 X_{3}^{2}
\end{gathered}
$$

Where $\mathrm{Y}(\mathrm{c})$ is calorific value and $\mathrm{X}_{1} \mathrm{X}_{2}$ and $\mathrm{X}_{3}$ are coded values for methanol, $\mathrm{NaOH}$ and temperature respectively.

Table 3. Regression coefficient and corresponding probability values ( $p$ values) for specific response (calorific value) for palm biodiesel.

\begin{tabular}{lll}
\hline $\begin{array}{l}\text { Parameter } \\
\text { (coefficient) }\end{array}$ & \multicolumn{2}{c}{ Calorific value (c) } \\
\cline { 2 - 3 } coefficient & p-value \\
\hline Constant $\left(\mathrm{A}_{0}\right)$ & -3031.33 & 0.110189 \\
$\mathrm{X}_{1}\left(\mathrm{~A}_{1}\right)$ & 1174.911 & $0.00017^{*}$ \\
$\mathrm{X}_{2}\left(\mathrm{~A}_{2}\right)$ & 4893.243 & $0.015437^{*}$ \\
$\mathrm{X}_{3}\left(\mathrm{~A}_{3}\right)$ & 141.3478 & $0.019215^{*}$ \\
$\mathrm{X}_{1} \mathrm{X}_{2}\left(\mathrm{~A}_{4}\right)$ & -3.4155 & 0.953784 \\
$\mathrm{X}_{1} \mathrm{X}_{3}\left(\mathrm{~A}_{5}\right)$ & 2.483217 & 0.07766 \\
$\mathrm{X}_{2} \mathrm{X}_{3}\left(\mathrm{~A}_{6}\right)$ & -19.9124 & 0.289679 \\
$\mathrm{X}_{1} \mathrm{X}_{1}\left(\mathrm{~A}_{7}\right)$ & -52.2752 & $4.09 \mathrm{E}-05^{*}$ \\
$\mathrm{X}_{2} \mathrm{X}_{2}\left(\mathrm{~A}_{8}\right)$ & -4617.75 & $0.003257^{*}$ \\
$\mathrm{X}_{3} \mathrm{X}_{3}\left(\mathrm{~A}_{9}\right)$ & -1.46595 & $0.008598^{*}$ \\
\hline
\end{tabular}

${ }^{*} p<0.05$

Table 3 represents the ANOVA analysis of design variables where values of coefficients and $p$-values are represented for the three responses. The $p$-values are used as a tool to check the significance of each coefficient, which also indicate the interaction strength between each independent variable. A $p$ value less than 0.05 indicate that the factor interacted significantly with the response. It is observed that all the $p$ values are smaller than 0.05, except methanol-alkali concentration and alkali concentration- temperature on calorific value. The p-value 0.00004 obtained from methanol concentration $\left(\mathrm{X}_{1} \mathrm{X}_{1}\right)$ indicates that methanol has greater impact on calorific value than alkali and temperature. The calculation of regression analysis also gives the value of the determination coefficient $R^{2}$ represented in table 4 .

Table 4. $R^{2}$ values for the ANOVA analysis of the three response output.

\begin{tabular}{ll}
\hline $\mathbf{R}^{2}$ values & Calorific value (c) \\
\hline Palm biodiesel & 0.977974 \\
\hline
\end{tabular}

\subsection{Analysis of Calorific Value by Response Surface Plot}

The relationship between coded variables and responses can be better understood by examining the series of $3 \mathrm{D}$ line plots. These 3D lines display the effect of variation of two factors while the third is kept constant. Due to three coded levels and the three coded variables total nine combinations are possible for each response. The plots are created with the aim to observe optimum condition from predicted values.

For palm biodiesel Figure 3 represents the effect of methanol, $\mathrm{NaOH}$ concentration and temperature on calorific value. When temperature is kept constant at $55^{\circ} \mathrm{C}$ [fig. $\left.3(\mathrm{C})\right]$, maximum calorific value $9297.206 \mathrm{kcal} / \mathrm{kg}$ was observed at $0.4 \mathrm{gmNaOH}$ and $12.5 \mathrm{ml}$ methanol. At $0.3 \mathrm{gm} \mathrm{NaOH}$ and $50^{\circ} \mathrm{C}$ temperature the calorific value has a minimum value $9190 \mathrm{kcal} / \mathrm{kg}$, when $12.5 \mathrm{ml}$ methanol was constant. As the temperature increases the calorific value increases. But after $57^{\circ} \mathrm{C}$ the calorific value decreases. Similar effect has shown for other $\mathrm{NaOH}$ concentration. Thus combined $\mathrm{NaOH}$ and temperature has more effect on calorific value than alone $\mathrm{NaOH}$ or temperature. The maximum value obtained at $55^{\circ} \mathrm{C}$ temperature and $0.4 \mathrm{gm} \mathrm{NaOH}$ concentration when $12.5 \mathrm{ml}$ methanol is constant [fig.3 (B)]. When methanol is kept constant [fig. 3 (A)] an increase or decrease in $\mathrm{NaOH}$ concentration yields calorific values with slight changes, but when $\mathrm{NaOH}$ is kept constant [fig.3 (B)] an increase or decrease in methanol concentration yields calorific values with greater changes. This indicates that the changes in methanol concentration have more effect on calorific value than changes in $\mathrm{NaOH}$ concentration.

From all nine surface plots for calorific value it is clear that the methanol, $\mathrm{NaOH}$ concentration and temperature at central values yield maximum calorific value. Changes in methanol, $\mathrm{NaOH}$ concentration and temperature from central values minimized the calorific values which support the theory. So, $12.5 \mathrm{ml}$ methanol, $0.4 \mathrm{gm} \mathrm{NaOH}$ and $55^{\circ} \mathrm{C}$ 
temperature are optimum condition for palm biodiesel production with maximum calorific value.
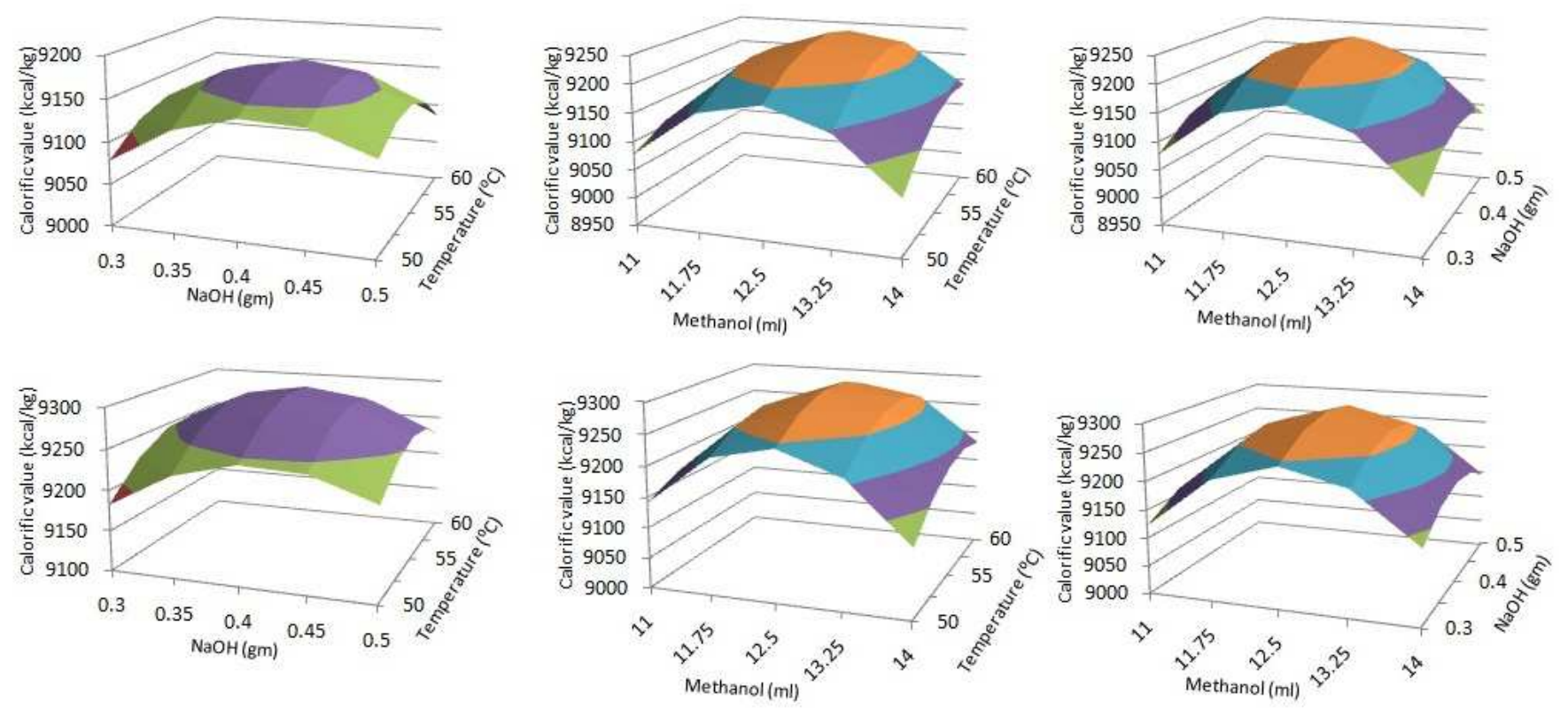

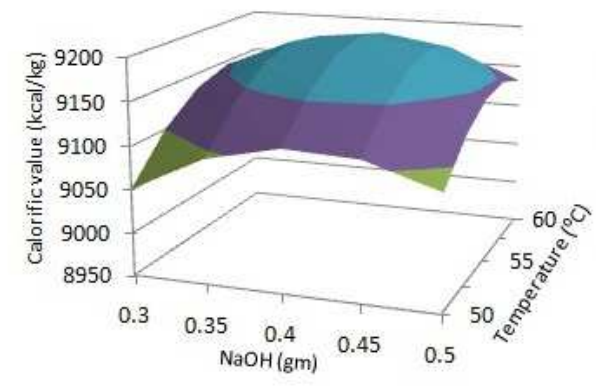

A

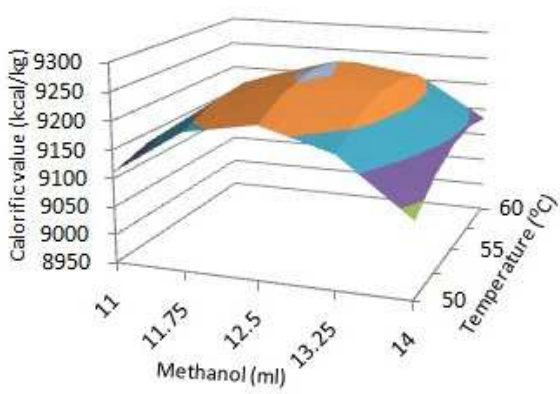

B

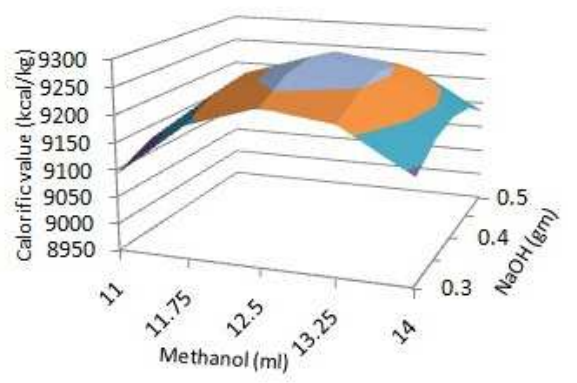

C

Figure 3. 3-D response surface plots for all design conditions.

(A) Effects of temperature and $\mathrm{NaOH}$ on calorific value at constant methanol (ml), (B) Effects of temperature and methanol on calorific value at constant $\mathrm{NaOH}$ concentration (gm), and (C) Effects of methanol and $\mathrm{NaOH}$ on calorific value at constant temperature $\left({ }^{\circ} \mathrm{C}\right)$.

\subsection{Optimization and Method Validation}

Optimal aspects for production process are confirmed with the assist of a contour plot. The plot was developed by plotting $\mathrm{NaOH}$ concentration (y-axis) against methanol concentration (x-axis) for a series of predicted calorific values at a constant $55^{\circ} \mathrm{C}$ temperature. Figure 4 represents the contour curve where different values articulated a different zone. Here, $\mathrm{X}$ is methanol concentration $(\mathrm{ml} / 50 \mathrm{ml}$ oil), $\mathrm{Y}$ is $\mathrm{NaOH}$ concentration $(\mathrm{gm} / 50 \mathrm{ml}$ oil) and $\mathrm{Z}$ is calorific value $(\mathrm{kcal} / \mathrm{kg})$.

Experimentally, only one combination produced maximum calorific value (Table 2). From the curve, it is found that several combinations of $\mathrm{NaOH}$ concentrations and methanol are likely to produce the same line. It can be observed that a smaller portion on the middle of the curve consists of high calorific value $(9290 \mathrm{kcal} / \mathrm{kg})$ zones and smaller lower calorific value $(9150 \mathrm{kcal} / \mathrm{kg})$ zone at the left corner.

A higher calorific value zone could be obtained using a $\mathrm{NaOH}$ concentrations range of $0.375-0.440 \mathrm{gm} / 50 \mathrm{ml}$ oil and methanol 12.4-12.6 ml/50 ml oil. While a lower calorific value zone resulted from a $\mathrm{NaOH}$ concentrations range of $0.3-0.31 \mathrm{gm} / 50 \mathrm{ml}$ oil and methanol $11-11.1 \mathrm{ml} / 50 \mathrm{ml}$ oil. This curve signifies that high calorific value is more responsive to the combined effect of $\mathrm{NaOH}$ and methanol concentrations.

Table 5. Experimental and predicted calorific values for method validation experiment.

\begin{tabular}{lllll}
\hline $\begin{array}{l}\text { Methanol } \\
\left(\mathbf{X}_{\mathbf{1}}\right)(\mathbf{m l})\end{array}$ & $\begin{array}{l}\text { NaOH } \\
\left(\mathbf{X}_{2}\right)(\mathbf{g m})\end{array}$ & $\begin{array}{l}\text { Temperature } \\
\left(\mathbf{X}_{\mathbf{3}}\right)\left({ }^{\circ} \mathbf{C}\right)\end{array}$ & \multicolumn{2}{c}{ Calorific value $(\mathbf{c})(\mathrm{kcal} / \mathbf{k g})$} \\
\hline 11 & 0.3 & 50 & Experimental & Predicted \\
\hline 11 & 0.4 & 55 & 9111.677 & 9103.06 \\
12.5 & 0.4 & 50 & 9145.384 & 9164.451 \\
14 & 0.5 & 60 & 9233.589 & 9239.407 \\
\hline
\end{tabular}

Validation of the process is done by selecting a few values randomly from the combinations. The results are presented in Table 5 shows that the experimental values are close to 
predicted value. $\mathrm{NaOH}$ concentration and temperature at central values yield maximum calorific value. Changes in methanol, $\mathrm{NaOH}$ concentration and temperature from central values minimized the calorific values which support the theory. As these chemical parameters produce higher calorific value, these parameters can be precise as the better production condition.

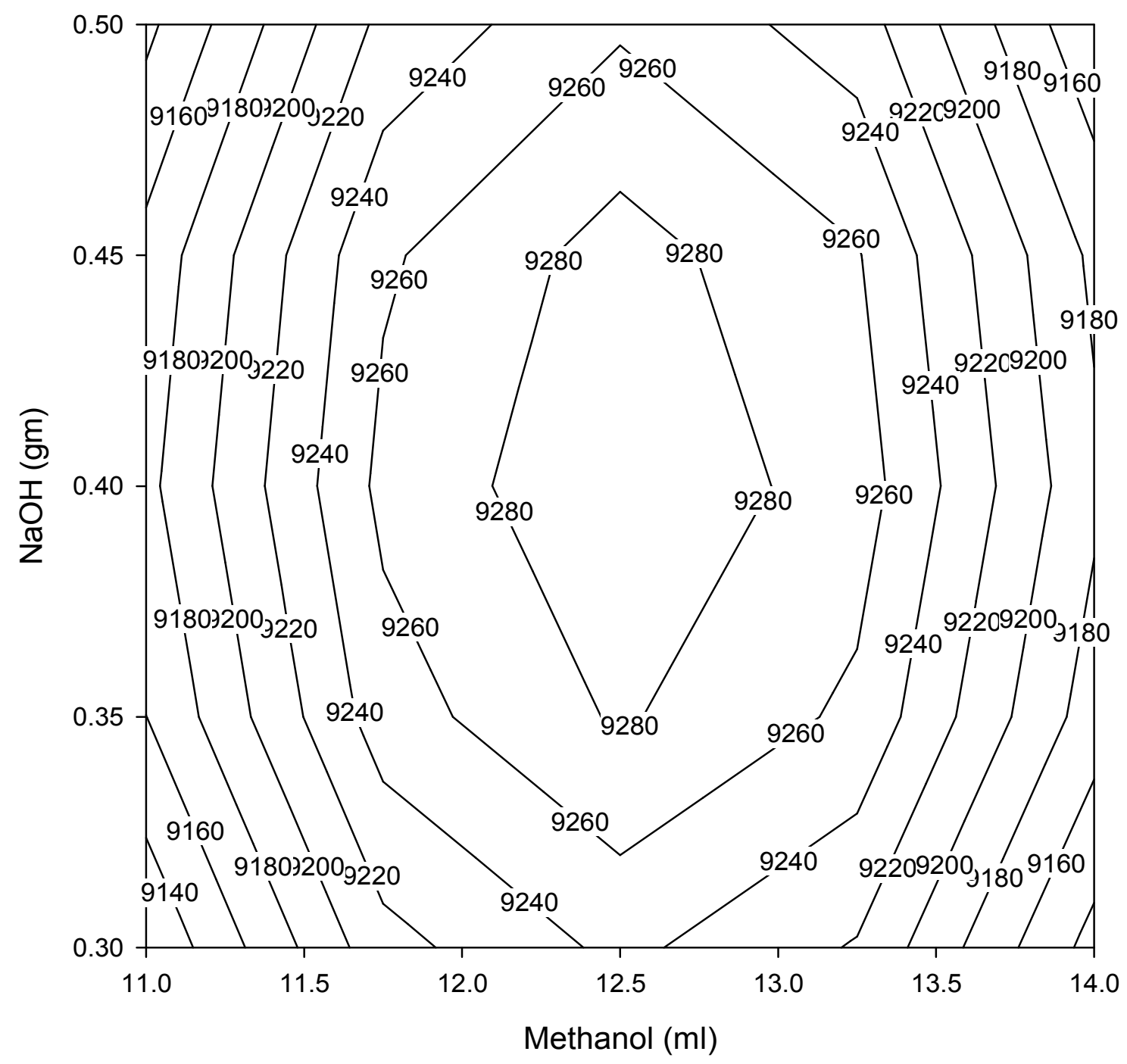

Figure 4. Effect of methanol and $\mathrm{NaOH}$ concentration on calorific value of palm biodiesel at constant $55^{\circ} \mathrm{C}$.

\section{Conclusion}

In this experiment response surface methodology was used, and a quadratic polynomial equation was obtained for each value by multiple regression analysis. Total 15 combinations of methanol, $\mathrm{NaOH}$ and temperature were employed to develop Box-Behnken experimental design. Qualities of resulted products were evaluated in terms calorific value. It was found that $12.5 \mathrm{ml}$ methanol $/ 50 \mathrm{ml}$ oil and $0.4 \mathrm{gmNaOH} / 50 \mathrm{ml}$ oil and $55^{\circ} \mathrm{C}$ temperature were optimum condition, where the calorific value of palm biodiesel is maximum $9297.206 \mathrm{kcal} / \mathrm{kg}$. The optimum condition will be used to investigate the effect of methanol, alkali concentration and temperature on reaction time and on other fuel properties of biodiesel.

\section{Acknowledgements}

The authors acknowledge Khulna University, Bangladesh for the financial and technical support and Department of Chemical Engineering of Bangladesh University of Engineering and Technology for chemical analysis.

\section{References}

[1] (2011) Commission services, Organization for Economic Cooperation and Development, [Online]. Available: http://www.inforse.dk/europe/dieret/WHY/why.html.

[2] (2011) International Energy Outlook 2010, U.S. Energy Information Administration,[Online]. Available: http://205.254.135.24/oiaf/ieo/highlights.html. 
[3] (2011) US Department of Energy on greenhouse gases, [Online]. Available: http://en.wikipedia.org/wiki/Fossil_fuel.

[4] (2011) U.S. Department of Energy and the U.S. Department of Agriculture, [Online]. Available: http://www.jatrophabiodiesel.org/bioDiesel.php.

[5] A. Nag, "Biofuels Refining and Performance", New York, NY: McGraw-Hill, 2007.

[6] S. Paweetida, J. Hiroi, K. Yoshikawa and T.Namioka, "Basic Chemical Reaction Study on Biodiesel Fuel Production from Plant Oil", Tokyo Institute of Technology, paper presented at 2nd AUN SEEDNet Regional Conference on New and Renewable Energy, Thailand, January 2010.

[7] R. Burton and L. Forer, (2015), "Introduction to Biofuels: Biodiesel and Straight Vegetable Oil", [online]. Available at: www.biofuels.coop/pdfs/1_intro.pdf.

[8] EG. Shay, "Diesel fuel from vegetable oil: status and opportunities", Biomass Bioenergy, 1993; 4(4):227^4-2, 1993.
[9] L. Attanatho, S.Magmee and P. Jenvanitpanjakul, "Factors Affecting the Synthesis of Biodiesel from Crude Palm Kernel Oil", the Joint International Conference on "Sustainable Energy and Environment (SEE)" 1-3 December 2004, HuaHin, Thailand.

[10] Box, G. E. P., Behnken, D. W., Technometrics 1960, 2, 455 475.

[11] Cocharn, W. G. and Cox, G. M., Experimental Designs, 2nd Ed., Wiley, New York 1992.

[12] Mamun, A. A., Siddiqua, S. and Babar, S. M. E, "Selection of an Efficient Method of Biodiesel Production from Vegetable Oil Based on Fuel Properties", International Journal of Trends and Technology, 2013, V4 (8):3289-3293.

[13] Babar, S.M.E., Song, S.J., Hasan, M.N. and Yoo, Y.S., "Experimental design optimization of the capillary electrophoresis separation of leucine enkephalin and its immune complex”, Wiley Inter Science, 2007. 